\title{
Winfried-Thomas Schneider
}

\section{Abkehr vom Verschuldensprinzip?}

\author{
Eine rechtsvergleichende Untersuchung zur Vertragshaftung (BGB, Code civil und \\ Einheitsrecht)
}

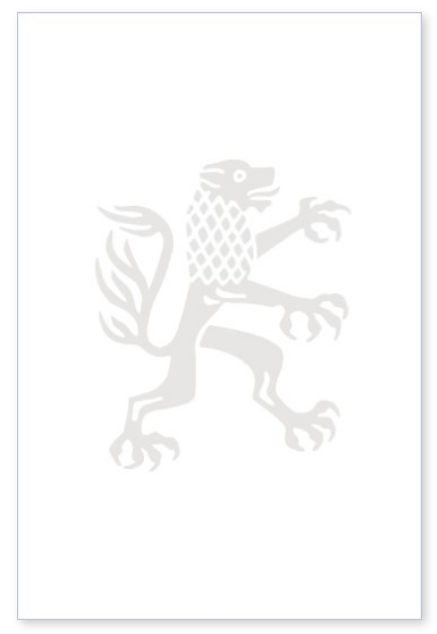

2007. XXIV, 514 Seiten. StudIPR 179

ISBN 978-3-16-151364-0

DOI 10.1628/978-3-16-151364-0

eBook PDF $104,00 €$
Winfried-Thomas Schneider untersucht das Verschulden als Voraussetzung der Vertragshaftung, dessen Bedeutung im internationalen und europäischen Vertragsrecht zunehmend schwindet. Das moderne Einheitsrecht geht, dem common law folgend, überwiegend vom Grundsatz der objektiven Vertragshaftung aus. Das französische Recht, das nach traditioneller Auffassung die vertragliche Haftung von einer 'faute' des Schuldners abhängig macht, versteht diesen Begriff heute allgemein als rein objektiven Verstoß gegen eine Vertragspflicht und damit als Synonym vertraglicher Nichterfüllung. Eine geplante Reform des französischen Obligationenrechts dürfte diese Entwicklung im Gesetz festschreiben. Das reformierte deutsche Schuldrecht orientiert sich an den Modellen des Einheitsrechts, will zugleich aber das »bewährte Verschuldensprinzip« nicht in Frage stellen. Im Anschluß an eine kurze Darstellung der historischen Grundlagen des Verschuldensprinzips in BGB und Code civil befaßt sich der Autor aus rechtsvergleichender Perspektive zunächst mit den Einschränkungen dieses Grundsatzes. Die hierfür ursächliche, vornehmlich durch die Schuldrechtsreform bewirkte Annäherung des deutschen Schuldrechts an das internationale Einheitsrecht ist jedoch bislang unvollständig geblieben. Das französische Recht zeigt aber, daß auch eine von traditionellen kontinentaleuropäischen Grundsätzen beherrschte Rechtsordnung in der Lage ist, sich zu einem modernen, den Ansprüchen des internationalen Rechtsverkehrs entsprechenden System fortzuentwickeln. Deshalb appelliert der Autor an den deutschen Gesetzgeber, seine Entscheidung, sich - vorerst - nicht vom Verschuldensprinzip lösen zu wollen, zu überdenken.

Winfried-Thomas Schneider Geboren 1974; Studium des deutschen und des französischen Rechts in Saarbrücken und Metz; Staatsexamen und Maîtrise en droit; Richter beim Landgericht in Saarbrücken, zur Zeit abgeordnet an das Bundesministerium der Justiz in Berlin und Lehrbeauftragter an der Universität des Saarlandes; 2006 Promotion.

Jetzt bestellen:

https://mohrsiebeck.com/buch/abkehr-vom-verschuldensprinzip-9783161513640?no_cache=1

order@mohrsiebeck.com

Telefon: $+49(0) 7071-923-17$

Telefax: +49 (0)7071-51104 